\title{
Evaluation of the factors associated with sublingual varices: a descriptive clinical study
}

\author{
N. Akkaya', D. Ölmez¹, G. Özkan² \\ 'Department of Dentomaxillofacial Radiology, Faculty of Dentistry, Hacettepe University, Ankara, Turkey \\ ${ }^{2}$ Department of Dentomaxillofacial Radiology, Faculty of Dentistry, Aydin Adman Menderes University, Aydin, Turkey
}

[Received: 2 September 2018; Accepted: 28 September 2018]

Background: Age is considered as an important factor for the development of sublingual varices (SV). It has been suggested that some other conditions such as gender, systemic diseases, smoking, denture wearing may play a role in aetiology. However, there are a limited number of studies investigating these associations. This study was perform to evaluate association between SV and the conditions which are described as possible risk factors previously.

Materials and methods: A total of 691 patients (470 females, 221 males) who attended for comprehensive clinical examination were included in the study. Age, gender, systemic health, venous varix of the lower extremities, smoking status, denture wearing were recorded during the history taking. SV were classified into two categories: stage 0 (few or none visible) and stage 1 (moderate or severe). Tongue photographs were taken from a group of these patients. For the evaluation of intra-observer reliability, 60 photographs of tongue were re-evaluated by the same observer. Intra-observer reliability was evaluated using Kappa statistics. Pearson $\chi^{2}$ test and Fisher's exact test were used to assess $S V$ in relation to each variable, and variables showing associations with $p<0.05$ were selected for the multivariable analysis, then logistic regression analysis was applied.

Results: Kappa value of intra-observer reliability was 0.91. SV were significantly associated with age (odds ratio $[O R]=1.08, p=0.000$ ), hypertension (OR=2.3, $p=0.007)$ and denture wearing $(O R=2.17, p=0.02)$.

Conclusions: The presence of SV is associated with hypertension and denture wearing as well as aging. More detailed studies are needed to prove causative relations between SV and systemic diseases. (Folia Morphol 2019; 78, 2: 325-330)

Key words: varicose veins/aetiology, age factor, dentures/adverse effect, hypertension/complications, tongue/blood supply, odds ratio

\section{INTRODUCTION}

Varices are abnormally dilated tortuous veins or venules, artery or lymphatic vessels; however, the term refers venous lesions for the oral cavity $[10,18]$. Sublingual varices (SV) involving the lateral branches of vena profunda linguae are common type of acquired vascular lesions $[8,26]$. This benign condition has been given various names including lingual or sublingual varicosities, phlebectasia linguae, caviar tongue, spots or lesions [18]. Although oral varices are most frequently seen on the ventral surface of the tongue, they may also occur on the lips and floor of the mouth. Less frequently a varix, which is a focal dilatation of vein, may occur on buccal mucosa, labial commissures, and sometimes soft and hard palate [18]. 
The clinical features of SV are usually multiple, irregular, blue-purple, elevated or papular blebs on the ventral and lateral border of the tongue. They are usually distributed from the posterior part bilaterally to the apex of tongue. The lesions are usually asymptomatic and frequently encountered during routine clinical examination [22].

Since incidence increases with aging, age is considered an important factor. Kleinman [16] stated that the condition is related to the aging process, and prior to the fifth decade, varices may be an indication of premature aging. Chronic cough [3], venous insufficiency [8], cardiovascular/cardiopulmonary diseases $[11,12,19]$, portal hypertension [14], diabetes mellitus [29], chronic vitamin C deficiency [2], smoking [12], denture wearing [1] have been suggested as predisposing factors for SV. There are limited number of studies which have been examined the association between SV and conditions listed above [1-3, 8, $11,12,16,19]$. The role of the systemic health on the development of SV is controversial. Ettinger and Manderson [8] stated that a person with varicose veins of the legs is likely to have lingual varicosities, but reverse is not necessarily true. Bean [3] reported that there was no connection between SV and systemic diseases. Lynge Pedersen et al. [19] found an association between sublingual varicosities and cardiovascular diseases (CVD) and medication. Recently, Hedström et al. [11] found an association between SV and hypertension; Al-Shayyab and Baqain [1] described that old age, female gender, denture wearing and CVD are the risk factors for SV. These results arises a question whether cardiovascular system diseases as a whole or only hypertensive disease is related to SV. Lazos et al. [18] emphasized that more detailed studies are needed to explain relations between varices and systemic diseases, which may contribute to early diagnosis of possible medical conditions during intraoral examination. Therefore, the purpose of this study was to investigate some potential risk factors suggested previously, including hypertensive disease, other diseases of the circulatory system, diabetes mellitus, varicose veins of lower extremities, smoking, and denture wearing for the development of SV in patients through a wide age range.

\section{MATERIALS AND METHODS}

The investigational protocol for the study was approved by the Non-Interventional Clinical Researches Ethics Board at the Hacettepe University (GO 16/647-
05) and was performed in accordance with the Helsinki Declaration. This cross-sectional clinical study was conducted on patients who attended the Department of Dentomaxillofacial Radiology, Hacettepe University for comprehensive clinical examination between April 2016 and October 2016. Before starting the study, tongue examination of 50 patients was made by 2 observers simultaneously as an exercise for the differentiation between few visible and moderate lesions as classified in the previous study [12]. All of the patients who agreed to participate in the study were examined by an investigator. Patients who could not clearly answered the questions about medical history were excluded from the study. Prior to clinical examination, demographic characteristics and historical information including age, gender, systemic health (hypertension, other CVD, diabetes mellitus), smoking status (never, current, former), and denture wearing were recorded for all subjects. At the end of the clinical examination, SV were classified. In order to examine ventral surface and lateral borders of the tongue and floor of the mouth, patients were asked to move the tongue upward and turn it to the left and then to the right. Using the criteria described by Hedström and Bergh [12], SV classified into two categories: grade 0 (few or none visible) (Fig. 1A) and grade 1 (moderate or severe) (Fig. 1B). To evaluate intra-observer reliability, tongue photographs were taken from a group of the patients. Sixty photographs were randomly selected by other investigator and re-examined by the same investigator 6 months after the initial examination. Before analysing data, intra-observer reliability was evaluated using Kappa statistic to ensure that there was no significant measurement error. Kappa value of intra-observer reliability was 0.91 . The agreement of measurements was found to be almost perfect according to the categorisation of Kappa statistic proposed by Fleiss [9].

\section{Statistical analysis}

Statistical analysis was performed by IBM SPSS Statistics, Version 20.0 (Armonk, NY: IBM Corp.). Preliminary analysis was carried out using Pearson $\chi^{2}$ test and Fisher's exact test to assess $\mathrm{SV}$ in relation to each variable, and variables showing associations with $p<0.05$ were selected for the multivariable analysis. Logistic regression was used to assess the association of SV with age, smoking, systemic diseases (yes/no), hypertension, other CVD, diabetes mellitus, varicose veins of lower extremities, and denture wearing. Odds ratios (OR) were 


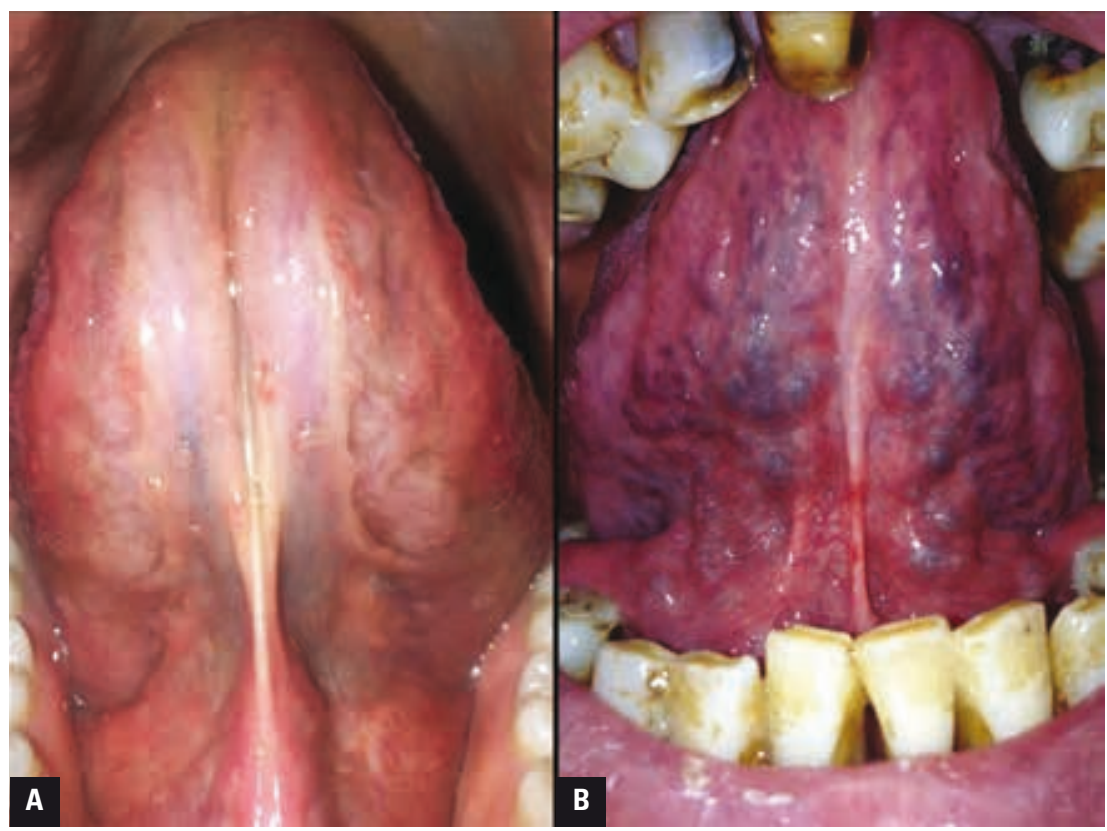

Figure 1. Sublingual varices classified into two categories using the criteria described by Hedström and Bergh [12]. Clinical appearances of the stages are shown in panel $\mathbf{A}$, grade 0 (few or none visible) and in panel $\mathbf{B}$, grade 1 (moderate or severe).

Table 1. Distribution of sublingual varices (SV) by genders; ${ }^{*} \mathrm{p}>0.05$

\begin{tabular}{lccc}
\hline SV & Female $(\mathbf{n}=\mathbf{4 7 0})$ & Male $(\mathbf{n}=\mathbf{2 2 1})$ & Total $(\mathbf{n}=\mathbf{6 9 1})$ \\
\hline Grade 0 & $345(73.4 \%)$ & $160(72.4 \%)$ & $505(73.1 \%)$ \\
Grade 1 & $125(26.6 \%)$ & $61(27.6 \%)$ & $186(26.9 \%)$
\end{tabular}

used to report the size of the associations. P-values less than 0.05 were considered to be statistically significant.

\section{RESULTS}

Seven hundred and fourteen patients were invited to participate in the study. The patients who refused to participate in the study $(n=7)$, and have unclear medical history $(n=16)$ were excluded. A total of 691 patients (470 females, 221 males) were included in the study. The patients were 18-88 years of age (mean $38.88 \pm 16$ years). The percentage of females $(68 \%)$ was higher than that of males $(p<0.001)$. The prevalence of SV was $26.9 \%$. Distribution of SV according to gender is presented in Table 1 . There was no statistically significant gender difference ( $p>0.05$ ). Figure 2 shows distribution of SV according to the age groups. There was a significant relation between age and SV $(p<0.001)$. The prevalence increases apparently for the patients older than 50 . The prevalence of SV according to risk factors evaluated and their significance values are presented in Table 2 .

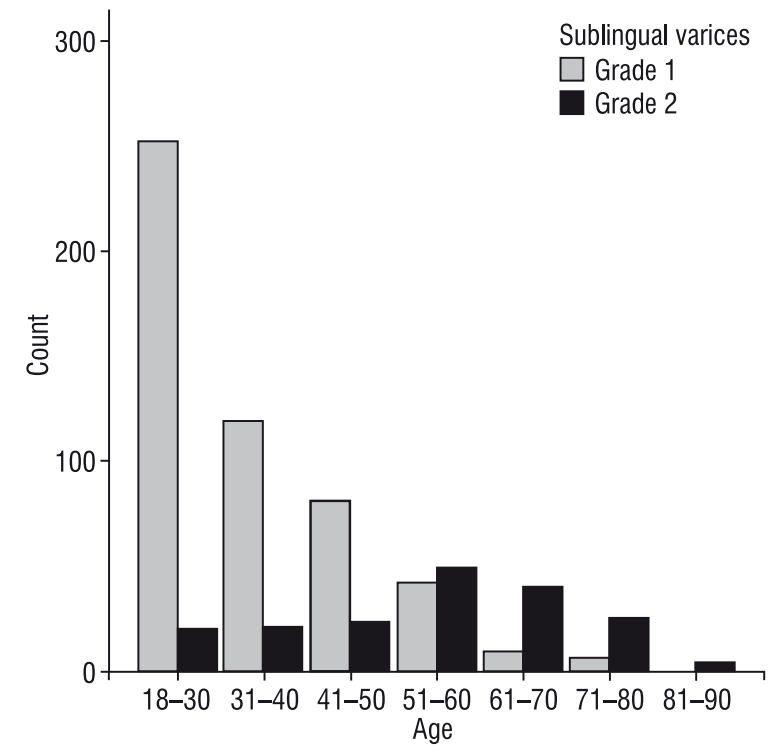

Figure 2. Distribution of sublingual varices according to age groups.

Logistic regression model was constructed to analyse the variables associated with higher probability of having SV. The independent variables included in 
Table 2. Prevalence of sublingual varices according to risk factors

\begin{tabular}{lccc}
\hline Variable & N & Sublingual varices & P \\
\hline Systemic diseases & 244 & $114(46.7 \%)$ & $<0.001$ \\
Cardiovascular diseases & 62 & $35(56.5 \%)$ & $<0.001$ \\
Hypertension & 86 & $63(73.3 \%)$ & $<0.001$ \\
Diabetes mellitus & 45 & $27(60.0 \%)$ & $<0.001$ \\
Venous varix of the lower extremities & 152 & $61(40.1 \%)$ & $<0.001$ \\
Denture wearing: & 74 & $54(73.0 \%)$ & $<0.001$ \\
Smoking status: & & & $<0.001$ \\
$\quad$ Current & 173 & $38(22.0 \%)$ & \\
$\quad$ Former & 84 & $40(47.6 \%)$ & $108(24.9 \%)$ \\
$\quad$ Never & 434 & & \\
\hline
\end{tabular}

*Pearson $\chi^{2}$ test with Fisher's exact test

Table 3. The influence of risk factors for sublingual varices by multivariable logistic regression model

\begin{tabular}{lccccc}
\hline Variable & B & SE & OR & P & 95\% Cl \\
\hline Age & 0.077 & 0.008 & 1.080 & $<0.001$ & $1.063-1.098$ \\
Hypertension & 0.837 & 0.312 & 2.309 & 0.007 & $1.254-4.252$ \\
Denture wearing & 0.777 & 0.335 & 2.175 & 0.020 & $1.128-4.193$ \\
\hline
\end{tabular}

$\mathrm{Cl}$ — confidence interval; $\mathrm{OR}$ — odds ratio; SE — standard error

the multivariable analysis were: age, smoking, denture wearing, systemic diseases, diabetes mellitus, hypertension, CVD, and venous varix of the lower extremities. The results of logistic regression analysis are presented in Table 3. Age (OR: 1.08, p < 0.001), hypertension (OR: 2.30, $p<0.05)$, and denture wearing (OR: 2.17, p < 0.05) were statistically significant risk factors for SV.

\section{DISCUSSION}

The prevalence of SV was $26.9 \%$ in this study. This result is consistent with a recent study using the same diagnostic criteria (26.5\%) [1]. However, the prevalence of SV varies from $4 \%$ to $68 \%$ in several studies $[6,8,13,15,17,22]$. These variations may be due to age differences of the study samples. Some of the earlier studies have been conducted on geriatric patients [13, 19, 20, 25]. In addition, there may be differences in diagnostic criteria, methodology and sampling procedures between the studies. In this study, previously described diagnostic criteria by Hedström et al. [12] were used. In this two-grade classification, minimal dilatation of veins has included in grade 0 , so that these lesions are not accepted as SV. It is not clear whether minimal dilatations were accepted as SV in the previous studies $[13,19]$. This classification is not in detail and it may be difficult to differentiate between minimum and moderate dilatations. For this reason, an exercise was made before starting the study and the tongue images of participants were re-examined by same investigator to evaluate intra-observer reliability. Intra-observer reliability was found 0.91 . Hedström et al. [11] reported 0.87 inter-observer agreement using the same diagnostic criteria. These intra- and inter-observer values shows that reproducibility and repeatability of the classification system is satisfactory.

In the present study, there was no significant difference in both genders. This finding is consistent with the previous studies $[12,21]$. Contrary to this finding, Al-Shayyab and Baqain [1] found that females were more likely to have sublingual varies. They proposed that SV may be influenced by hormonal conditions.

In this study, the prevalence of SV showed a significant increase with advancing age, especially after the 50 years old. This finding is consistent with the previous studies $[8,12,16]$. It has been thought that loss of supporting connective tissue of vessels with aging may lead to venous dilatation [23]. How- 
ever, SV may also occur in individuals younger than 50 years. Kleinman [16] suggested that this finding may be related to premature aging. However, it is unclear which mechanism triggers the onset of this condition in younger people. Perhaps the main factor may be an underlying systemic disease, and the increased incidence with advanced age may be due to an increase in the incidence of systemic diseases with age. Wolff et al. [28] found that healthy, non-medicated persons, ranging in age between 20 and 95 years, had no oral mucosal changes. These authors noted that aging alone has not a significant effect on the oral mucosa and its protective defence mechanisms, when individuals are healthy. They emphasized that age-related oral mucosal changes may be associated with systemic diseases, malnutrition, medication, and wearing of ill-fitting dentures. These results may also be valid for SV.

The present study showed that there was an association between SV and hypertension (OR: 2.30, $p<0.05)$ and denture wearing (OR: 2.17, $p<0.05$ ). Hypertension and denture wearing raised the probability of having SV approximately two times. However, aging has less influence on development of SV (OR: 1.08, $p<0.001$ ). This finding is consistent with the previous study reported that SV may be used as an indicator of hypertension (OR: 2.25, p = 0.021) [11]. Lynge Pedersen et al. [19] found a relationship between SV and CVD and medication. The association between SV and CVD has also stated in another study [12]. In the light of these previous observations, in our study, CVD were classified as hypertension and other CVD. This classification has shown that hypertension may be predisposing factor for the development of SV, as well as aging. If this association reflects true relationship, it will be important for undiagnosed hypertensive cases.

Denture wearing may play a role as a contributing factor for the development of SV. It has been well known that especially ill-fitting dentures are related to oral mucosal lesions. Since SV are considered as normal age-related degenerative changes of the tissue by several investigators, they are usually excluded from the studies on oral mucosal lesions [7, 24, 27]. Therefore, limited information is present about pathogenesis of this condition in the literature. No relation has been found between denture wearing and $S V$ in some previous studies $[5,15,22]$. On the other hand, denture wearing has been reported as a risk factor for SV in a recent study [1]. These dif- ferent results may be due to the fact that quality of dentures has not been evaluated during the studies. III-fitting dentures may contribute to the development of SV in the tissues that become susceptible to traumatic effects with age. In this study, denture quality was not evaluated; this is one of the limitations of the study. In the future studies, the effect of denture quality on the development of SV may be examined.

The prevalence of SV in ex-smokers was higher than that of current smokers in this study. Therefore, smoking was not found as a contributory factor. This finding is not consistent with the previous observations [1, 12]. This result might be related to the fact that smoking has a preventive effect on the development of varicose veins due to vasoconstrictive effect of nicotine [4].

It has been suggested that chronic coughing could cause a recurrent increase in venous pressure because of avalvular venous system of the tongue; so that it might be a contributing factor [8]. In this study this variable could not be investigated because a sufficient number of subjects were not found. Chronic vitamin $C$ deficiency has also been previously reported as an associated factor [2]. Because of non-invasive study design, we did not include this variable.

The limitation of our study is that patients' medical health information was based on their own statements. Occult diseases that may be present in the participants could affect the results. Because of cross-sectional data, the results reflect only associations; therefore, cannot be generalised. More detailed studies are needed to prove causative relations between SV and systemic diseases.

\section{CONCLUSIONS}

The findings of this study revealed that presence of $\mathrm{SV}$ is associated with hypertension and denture wearing. The definition of these possible implications is important for the early recognition of the disease and referral for treatment of the patients.

\section{REFERENCES}

1. Al-Shayyab MH, Baqain ZH. Sublingual varices in relation to smoking, cardiovascular diseases, denture wearing, and consuming vitamin rich foods. Saudi Med J. 2015; 36(3): 310-315, doi: 10.15537/smj.2015.3.10429, indexed in Pubmed: 25737173.

2. Andrews J, Letcher $M$, Brook M. Vitamin C supplementation in the elderly: a 17-month trial in an old persons' home. $\mathrm{Br}$ Med J. 1969; 2(5654): 416-418, indexed in Pubmed: 5781487.

3. Bean WB. The caviar lesion under the tongue. Trans Am Clin Climatol Assoc. 1952; 64: 40-51, indexed in Pubmed: 13136210. 
4. Chalon S, Moreno H, Benowitz NL, et al. Nicotine impairs endothelium-dependent dilatation in human veins in vivo. Clin Pharmacol Ther. 2000; 67(4): 391-397, doi: 10.1067/ mcp.2000.105153, indexed in Pubmed: 10801248.

5. Corbet EF, Holmgren CJ, Phillipsen HP. Oral mucosal lesions in 65-74-year-old Hong Kong Chinese. Community Dent Oral Epidemiol. 1994; 22(5 Pt 2): 392-395, indexed in Pubmed: 7835037.

6. Corrêa PH, Nunes LC, Johann AC, et al. Prevalence of oral hemangioma, vascular malformation and varix in a Brazilian population. Braz Oral Res. 2007; 21(1): 40-45, indexed in Pubmed: 17384854.

7. Espinoza I, Rojas R, Aranda W, et al. Prevalence of oral mucosal lesions in elderly people in Santiago, Chile. J Oral Pathol Med. 2003; 32(10): 571-575, indexed in Pubmed: 14632931.

8. Ettinger RL, Manderson RD. A clinical study of sublingual varices. Oral Surg Oral Med Oral Pathol. 1974; 38(4): 540-545, indexed in Pubmed: 4528384.

9. Fleiss, JL. Statistical methods for rates and proportions. 2nd ed. New York: John Wiley. 1981.

10. Ghom AG, Ghom SA. Textbook of Oral Medicine. 3th ed. New Delhi: Jaypee Brothers. 2014.

11. Hedström L, Albrektsson M, Bergh $\mathrm{H}$. Is there a connection between sublingual varices and hypertension? BMC Oral Health. 2015; 15: 78, doi: 10.1186/s12903-015-0054-2, indexed in Pubmed: 26163474.

12. Hedström $L$, Bergh $H$. Sublingual varices in relation to smoking and cardiovascular diseases. Br J Oral Maxillofac Surg. 2010; 48(2): 136-138, doi: 10.1016/j. bjoms.2009.05.005, indexed in Pubmed: 19540027.

13. Jainkittivong A, Aneksuk V, Langlais RP. Oral mucosal conditions in elderly dental patients. Oral Dis. 2002; 8(4): 218-223, indexed in Pubmed: 12206403.

14. Jassar $P$, Jaramillo $M$, Nunez DA. Base of tongue varices associated with portal hypertension. Postgrad Med J. 2000; 76(899): 576-577, indexed in Pubmed: 10964125.

15. Kaplan I, Moskona D. A clinical survey of oral soft tissue lesions in institutionalized geriatric patients in Israel. Gerodontology. 1990; 9(2): 59-62, indexed in Pubmed: 2133459.

16. Kleinman HZ. Lingual varicosities. Oral Surg Oral Med Oral Pathol. 1967; 23(4): 546-548, indexed in Pubmed: 5227407.

17. Kovac-Kovacic M, Skaleric U. The prevalence of oral mucosal lesions in a population in Ljubljana, Slovenia. J Oral Pathol Med. 2000; 29(7): 331-335, indexed in Pubmed: 10947249.
18. Lazos JP, Piemonte ED, Panico RL. Oral varix: a review. Gerodontology. 2015; 32(2): 82-89, doi: 10.1111/ger.12074, indexed in Pubmed: 23992044.

19. Lynge Pedersen AM, Nauntofte B, Smidt D, et al. Oral mucosal lesions in older people: relation to salivary secretion, systemic diseases and medications. Oral Dis. 2015; 21(6): 721-729, doi: 10.1111/odi.12337, indexed in Pubmed: 25754744.

20. Mozafari PM, Dalirsani Z, Delavarian Z, et al. Prevalence of oral mucosal lesions in institutionalized elderly people in Mashhad, Northeast Iran. Gerodontology. 2012; 29(2): e930-e934, doi: 10.1111/j.1741-2358.2011.00588.x, indexed in Pubmed: 22136071.

21. Mumcu G, Cimilli $H$, Sur $H$, et al. Prevalence and distribution of oral lesions: a cross-sectional study in Turkey. Oral Dis. 2005; 11(2): 81-87, doi: 10.1111/j.16010825.2004.01062.x, indexed in Pubmed: 15752080.

22. Nevalainen MJ, Närhi TO, Ainamo A. Oral mucosal lesions and oral hygiene habits in the home-living elderly. J Oral Rehabil. 1997; 24(5): 332-337, indexed in Pubmed: 9183025.

23. Neville BW, Damm DD, Allen CM, et al. Oral \& Maxillofacial Pathology, 4th ed. Philadelphia, USA: WB Saunders. 2002.

24. Pentenero $M$, Broccoletti $R$, Carbone $M$, et al. The prevalence of oral mucosal lesions in adults from the Turin area. Oral Dis. 2008; 14(4): 356-366, doi: 10.1111/j.16010825.2007.01391.x, indexed in Pubmed: 18410578.

25. Rabiei M, Kasemnezhad E, Masoudi rad H, et al. Prevalence of oral and dental disorders in institutionalised elderly people in Rasht, Iran. Gerodontology. 2010; 27(3): 174-177, doi: 10.1111/j.1741-2358.2009.00313.x, indexed in Pubmed: 19702672.

26. Southam JC, Ettinger RL. A histologic study of sublingual varices. Oral Surg Oral Med Oral Pathol. 1974; 38(6): 879-886, indexed in Pubmed: 4531618.

27. Triantos D. Intra-oral findings and general health conditions among institutionalized and non-institutionalized elderly in Greece. J Oral Pathol Med. 2005; 34(10): 577-582, doi: 10.1111/j.1600-0714.2005.00356.x, indexed in Pubmed: 16202076.

28. Wolff A, Ship JA, Tylenda CA, et al. Oral mucosal appearance is unchanged in healthy, different-aged persons. Oral Surg Oral Med Oral Pathol. 1991; 71(5): 569-572, indexed in Pubmed: 2047098.

29. Vasconcelos BC, Novaes M, Sandrini FA, et al. Prevalence of oral mucosa lesions in diabetic patients: a preliminary study. Braz J Otorhinolaryngol. 2008; 74(3): 423-428, indexed in Pubmed: 18661018. 